\title{
Identifying International Assignees At Risk for Premature Departure: The Interactive Effect of Outcome Favorability and Procedural Fairness
}

\author{
Ron Garonzik \\ Hay/McBer Corporation
}

\author{
Joel Brockner \\ Columbia University
}

\author{
Phyllis A. Siegel \\ Rutgers, The State University of New Jersey
}

\begin{abstract}
Two studies examined factors that predict expatriate managers' tendencies to think seriously about departing prematurely from their international assignments. Previous research (conducted outside of the expatriate context) has shown that individuals' willingness to stay with or leave their positions is an interactive function of outcome favorability and procedural fairness. A conceptually analogous interaction effect was found in the present studies. Whereas expatriates more seriously thought of departing prematurely when they perceived the non-work-related outcomes of their overseas assignments to be less favorable, this tendency was much less pronounced when procedural fairness was relatively high. Theoretical and practical implications are discussed, as are limitations of the studies and suggestions for future research.
\end{abstract}

The consequences of managers' international assignments are of great significance, both to the organization and to the managers themselves. From the organization's perspective, whether international assignees successfully complete their tour of duty is a matter of considerable importance (Bird \& Dunbar, 1991; Black, Gregersen, \& Mendenhall, 1992; Naumann, 1992). Moreover, international assignments may have significant 'effects on managers' professional and personal lives. For example, international assignments may affect managers' longer-term career prospects, either inside their employing organization (Adler, 1996; Grant, 1997) or outside of it.

Given the many significant consequences of expatriation, it is both practically and theoretically important to understand the factors that make expatriation more or less successful (Black, Mendenhall, \& Oddou, 1991). Although the success or failure of expatriation has been conceptualized in a variety of ways, one frequent operational definition is the extent to which managers

Ron Garonzik, Hay/McBer Corporation, Boston, Massachusetts; Joel Brockner, Graduate School of Business, Columbia University; Phyllis A. Siegel, Faculty of Management, Rutgers, The State University of New Jersey.

Ron Garonzik and Joel Brockner contributed equally to this research; their order of authorship is random.

We thank Allan Bird, Ya-Ru Chen, Chris Earley, Mark Mendenhall, and Batia Wiesenfeld for their constructive comments on an earlier version of the article. We also are extremely grateful to the late David McClelland, who not only offered helpful comments on an earlier version of the article but who also served more generally as a source of guidance and inspiration for many years.

Correspondence concerning this article should be addressed to Joel Brockner, 715 Uris Hall, Columbia University, New York, New York 10027. Electronic mail may be sent to jb54@columbia.edu. prematurely depart from their international assignments. Studies have shown that the costs of premature departure may be considerable to the organization, the expatriates, or both. For example, it has been reported that the average annual cost to send an employee overseas for a year or two is in the range of $\$ 250,000-300,000$ (Milkovich \& Newman, 1996). Thus, for organizations that have a sizable number of expatriates, the total cost of premature repatriation may be enormous. Costs to the expatriates may include threatened career advancement, reduced managerial selfconfidence, and lowered prestige in the eyes of their peers.

The purpose of the present research is to identify factors that lead expatriate managers to think seriously about departing prematurely from their international assignments. Theory and research have suggested that turnover typically is preceded by several related withdrawal cognitions, such as serious thoughts of leaving and the intention to turnover (Mobley, 1982; Naumann, 1992; Shaffer \& Harrison, 1998). Moreover, previous research has found moderate-to-strong relationships between behavioral intentions and actual behavior, both generally in social psychology (Ajzen \& Fishbein, 1980) and specifically in the context of organizational turnover (Mobley, 1982; Naumann, 1992). For example, Steel and Ovalle (1984) reported a weighted average correlation of .50 between intention to turnover and actual turnover in their meta-analytic review. Thus, expatriates who are thinking seriously about departing prematurely may be described as being at risk to leave. Given the magnitude of the potential costs associated with premature expatriate departure, it is important to identify those who are at risk.

The potential conceptual advances offered by the present research are threefold. First, we seek to extend the literature on premature expatriate departure by providing a theory-driven analysis of some of its antecedents. More specifically, the present studies are grounded in a considerable body of theory and research 
in organizational justice (e.g., Greenberg, 1990). Second, the theoretical underpinning of the present studies offers an extension to existing models of expatriate adjustment and turnover (e.g., Black et al., 1991; Naumann, 1992), which suggests that expatriates' thoughts of premature departure may be influenced by a variety of factors. The existing models, however, have not considered how the various factors combine with each other to influence expatriates' thoughts of premature departure. The organizational-justice framework guiding the present studies suggests that several antecedents of expatriates' withdrawal cognitions interact to predict the extent to which they are seriously thinking of departing prematurely.

A third goal of the present studies is to extend the generality of organizational-justice theory. Although justice factors have been shown to influence a variety of important work attitudes and behaviors (e.g., Folger, 1993; Greenberg, 1996), few studies have examined the role of fairness perceptions as predictors of expatriates' reactions.

\section{Theoretical Grounding}

Organizational psychologists have shown that employees' work attitudes and behaviors are jointly determined by outcomes (i.e., what happens) and procedures (i.e., how things happen). Outcome factors have been considered by social exchange theorists (e.g., Blau, 1964). According to this viewpoint, employees give back to the organization (e.g., show signs of commitment) in proportion to the perceived favorability of the outcomes received from the organization. Relevant outcomes may be economic (e.g., favorable levels of compensation) or psychological (e.g., individuals' perceptions that they are valued and respected by their employers).

The role of procedural fairness has been discussed extensively by organizational justice theorists (e.g., Folger \& Greenberg, 1985; Greenberg, 1987; Lind \& Tyler, 1988). According to these viewpoints, employees will be more organizationally committed (e.g., they will be less likely to think of leaving) to the extent that organizational authorities use fair procedures in planning and implementing decisions. Individuals' perceptions of procedural faimess, moreover, are based on two categories of factors: (a) the structural aspects of decision processes, such as whether people are allowed to provide input into decisions (Thibaut \& Walker, 1975), and (b) the interpersonal behavior of those responsible for implementing decisions (also known as interactional justice; Bies, 1987), such as whether they treated the affected parties with dignity and respect.

The present research examines whether expatriates' thoughts of premature departure are affected by both the outcomes associated with their overseas assignment as well as the procedural fairness exhibited by organizational authorities. Interestingly, many recent studies (conducted outside of the expatriation context) have shown that outcome favorability and procedural faimess combine interactively to influence employees' attitudes and behaviors. It is therefore plausible that expatriates' thoughts of premature departure also will be an interactive function of outcome favorability and procedural faimess. Brockner and Wiesenfeld (1996) reviewed 45 independent samples that showed that individuals' perceptions of outcome favorability had much less of an impact on a variety of dependent variables (including withdrawal cognitions) when they perceived the procedures enacted by organizational authorities to be relatively fair.

A number of explanations have been advanced to account for the interactive relationship between outcome favorability and procedural fairness. It is beyond the scope of the present research to describe and compare the various explanations (but see Brockner \& Wiesenfeld, 1996, for a review). Moreover, the present studies were not designed to be a critical test of competing explanations. Rather, our primary purpose was to evaluate whether expatriates' thoughts of premature departure varied as a function of the interaction between outcome favorability and procedural fairness. Specifically, whereas expatriates were expected to be more seriously thinking of departing prematurely when the outcomes associated with their overseas assignment were relatively unfavorable, this tendency was expected to be less pronounced when procedural fairness was relatively high.

\section{Outcome Favorability in the Present Research}

Although many outcomes of significance to expatriates reside in the workplace (e.g., compensation, feeling valued), the outcomes selected for investigation in the present studies referred to the nonwork aspects of expatriates' assignments. Nonwork factors, such as living conditions, health care, and the perceived adjustment of participants' spouse or significant other, were chosen for several reasons. First, previous research has shown that the perceived favorability of these nonwork outcomes is meaningful to expatriates; for example, it predicts the extent to which expatriates consider departing prematurely from their overseas assignments (Black et al., 1992; Shaffer \& Harrison, 1998). Second, previous research examining the interactive relationship between outcome favorability and procedural fairness outside of the expatriate context invariably has examined work-related outcomes (e.g., Greenberg, 1994). By focusing on nonwork factors in the present studies, we evaluated whether the outcomes associated with a broader array of factors (than those residing in the workplace) interact with procedural fairness to influence employees' work attitudes and behaviors.

\section{Procedural Fairness in the Present Research}

Procedural faimess in the present research referred to expatriates' perceptions of the methods generally used by the parent organization to plan and implement decisions. Participants rated the fairness of the organization's usual procedures in making decisions, which may include, but need not be limited to, their expatriate experience (e.g., compensation, work assignments, etc.). Previous research has shown that perceptions of procedural fairness are related to various indexes of organizational commitment, including the desire to remain with (rather than depart from) the organization (Brockner \& Wiesenfeld, 1996). Moreover, the procedural fairness of an organization relates to several components of Naumann's (1992) model of expatriate turnover, such as corporate culture (i.e., the perceived fairness of how things are done around here).

In sum, we conducted two studies that examined the extent to which expatriates were thinking seriously about departing prematurely from their international assignments as a function of their perceptions of (a) the favorability of the nonwork outcomes of 
their assignments and (b) the procedural fairness of the organization's decision-making processes. Whereas expatriates were expected to be more seriously thinking of departing prematurely when outcomes were perceived to be less favorable, this tendency should have been less pronounced when procedures were seen as relatively fair.

\section{Study 1}

\section{Method}

Participants. Participants were 58 international assignees employed by a United States-based service company with significant international markets. The survey was mailed to all expatriates in the company; the response rate was $75 \%$. Participants were located in 20 countries drawn from five continents. The average age of participants in the sample was $\mathbf{3 7}$ years, and $95 \%$ of them were men. In addition, all of the participants in the main analyses were accompanied by a spouse or significant other on their assignment. The group was evenly divided between technical specialists and first-level managers versus second-level or higher managers (senior managers, managing directors, and vice presidents). Their average tenure with the company was 8.7 years. Participants had been in their assignments for an average length of 1.6 years at the time that the study was conducted. The typical length of an expatriate assignment in the organization was approximately 3 years.

Procedure. Participants were asked to complete a survey in the context of the organization's routine efforts at assessing and improving the quality of its human resource practices. Prior to receiving the survey, all participants received an in-house notice from the Vice President of International Personnel that informed them of the study's significance and implored them to take part. Ron Garonzik then mailed the survey to all participants. In the cover letter accompanying the survey, Garonzik introduced himself and described the basic purpose of the survey ("to gauge the experiences and reactions of international personnel to their assignments"). The cover letter also assured respondents that (a) their participation was voluntary, (b) their responses would be confidential, and (c) only aggregate data would be presented to the sponsoring organization.

Survey instrument. All of the measures were included in the survey, which consisted of more than 100 items and which entailed a comprehensive assessment of expatriates' perceptions of the assignment and the parent organization. The independent and dependent variables of the present study were embedded in the survey (Hay/McBer Co., 1996).

Dependent variable. Six items were developed to measure the extent to which participants were thinking seriously about departing prematurely from their expatriate assignment. A 6-point rating scale was used for each item, with endpoints labeled strongly disagree (1) and strongly agree (6). Items were coded such that higher scores reflected fewer thoughts of premature departure (or more of an expressed likelihood of remaining with the assignment). Sample items were, "I wouldn't seriously consider leaving my current job assignment prematurely," and "I often discuss with my spouse (or significant other) the possibility of returning to the U.S. prematurely" (reverse scored). Coefficient alpha was .76. Participants' responses to the six items were averaged into an index.

Independent variables: Outcome favorability. Seven items measured participants' perceptions of the favorability of the outcomes associated with their expatriate assignments. Six-point rating scales were used. Six of the seven items required participants to indicate how much they had adjusted to various aspects of their nonwork lives. Endpoints ranged from very unadjusted (1) to very adjusted (7). Aspects covered included (a) living conditions in general, (b) housing conditions, and (c) health care management. An additional item measuring an important nonwork outcome was, "How well has your spouse (or significant other) adjusted to living overseas?" Presumably, participants viewed their outcomes more favorably to the extent that they perceived adjustment to be higher. Re- sponses to the measures of outcome favorability were internally consistent (coefficient alpha $=.85$ ) and averaged into an index.

Procedural faimess. Whereas questions pertaining to outcome favorability referred specifically to the expatriate assignment, the measures of procedural fairness were intended to be more general, reflecting participants' judgments of the organizational climate of their work units based on typical day to day experiences (Hay/McBer Co., 1997; McClelland \& Burnham, 1995). Thus, evaluations of procedural fairness could be based on events associated with their expatriate assignment or organizational experiences encountered outside of the expatriate setting. Five items tapping various aspects of procedural faimess were included in the climate survey. Some of the items referred to the structural aspects of the organization's procedures (Leventhal, Karuza, \& Fry, 1980; Thibaut \& Walker, 1975), such as whether people were allowed to have input into the organization's decision-making policies ("Problems are solved and decisions are made at the lowest appropriate level in the business"). Other items focused on the interpersonal behavior of the parties responsible for planning and implementing decisions ("Employees are treated with respect and dignity in this company"). Six-point rating scales were used with endpoints consisting of diametrically opposed statements. All items were coded such that higher scores reflected stronger perceptions of procedural faimess. Coefficient alpha was .61. Participants' responses to the five measures of procedural justice were averaged into an index.

Control variables. Four factors that have been theoretically or empirically linked to expatriates' thoughts of premature departure were included in the survey (e.g., Black et al., 1992; Gregersen \& Black, 1992). The control variables consisted of (a) whether participants have had any prior international work experience (measured by either a "yes" or a "no" answer); (b) perceptions of predeparture training, which were assessed with four items (e.g., "I am satisfied with the quality of the predeparture preparation I underwent"; coefficient alpha $=.77$ ), (c) perceived support from the home office during their overseas assignment, which was based on six items (e.g., "Overall, I am satisfied with the level of support I have received from the home organization to help me solve work-related problems"; coefficient alpha $=.77$ ), and $(d)$ beliefs about being successfully repatriated on completion of their overseas assignment, which were based on five items (e.g., "I am confident that I will be repatriated in a manner that will take advantage of my international experience"; coefficient alpha $=.85$ ). Responses to the measures of predeparture training, perceived support from the home office, and beliefs concerning repatriation could range from thoroughty disagree (1) to thoroughly agree (6).

\section{Results and Discussion}

Summary statistics for and correlations between all of the continuous variables are reported in Table 1 . Four factors were significantly related to expatriates' thoughts of premature departure (perceived support from the home office, beliefs about being successfully repatriated, outcome favorability, and procedural fairness), all in the expected direction.

The primary hypothesis was tested with a hierarchical multiple regression. In the first step, we simultaneously entered the four control variables. As reported in Table 2, Step 1, the only one to attain significance was the measure of perceived support from the home office $(p<.01$ ). In the second step, we simultaneously added the main effects of outcome favorability and procedural faimess to the terms entered in Step 1. As can be seen in Table 2, Step 2, only the main effect of outcome favorability was significant $(p<.001)$, such that expatriates were more apt to think seriously about departing prematurely when their nonwork outcomes were more unfavorable.

Finally, and of greatest importance, the interaction between outcome favorability and procedural fairness was added in the 
Table 1

Summary Statistics and Correlations for Continuous Variables (Study 1)

\begin{tabular}{lcccccccc}
\hline \multicolumn{1}{c}{ Variable } & $M$ & $S D$ & 1 & 2 & 3 & 4 & 5 & 6 \\
\hline 1. Home office support & 2.83 & 0.93 & $(.77)$ & & & & & \\
2. Successful repatriation & 2.79 & 1.19 & $.58^{* *}$ & $(.85)$ & & & & \\
3. Predeparture training & 2.37 & 1.10 & $.52^{* *}$ & $.28^{*}$ & $(.77)$ & & & \\
4. Outcome favorability & 4.50 & 0.88 & $.35^{* *}$ & .15 & .18 & $(.85)$ & & \\
5. Procedural faimess & 3.67 & 0.92 & $.45^{* *}$ & $.34^{* *}$ & $.27^{*}$ & $.25^{*}$ & $(.61)$ & \\
$\begin{array}{l}\text { 6. Thoughts of premature } \\
\text { departure }\end{array}$ & 4.38 & 1.06 & $.51^{* *}$ & $.28^{*}$ & .11 & $.49^{* *}$ & $.32^{* *}$ & $(.76)$ \\
\hline
\end{tabular}

Note. Higher scores reflect greater levels of all variables except thoughts of premature departure, in which case higher scores reflect fewer thoughts of premature departure. All scores could range from 1-6. Coefficient alphas are in parentheses. One of the control variables (whether participants had overseas experience) was a categorical variable. We conducted a series of $t$ tests to evaluate whether this factor was related to any of the variables included in Table 1. The only significant effect emerged on the measure of predeparture training, $t(56)=2.49$, $p<.025$, such that perceptions of predeparture training were more favorable among participants who did not have (rather than did have) previous overseas experience $(M \mathrm{~s}=2.61$ and 1.94 , respectively).

$* p<.05$. *** $p<.01$.

third step; it was found to be significant $(p<.01)$. The fact that the sign of the beta weight was negative suggests that the interaction took the predicted form (i.e., that outcome favorability and thoughts of premature departure were more strongly related when procedural fairness was relatively low). To illustrate further the nature of the interaction effect, we classified participants as relatively high or low in their perceptions of procedural faimess on the basis of a median split. We then computed the correlation between outcome favorability and thoughts of premature departure for each of these two groups. As expected, expatriates' perceptions of outcome favorability were more closely related to their thoughts of premature departure among those who perceived relatively low levels of procedural fairness, $r(22)=.66, p<.01$, rather than high levels of procedural fairness, $r(32)=.32, p>.05$.

Although the measure of outcome favorability referred to tangible factors of known significance to expatriates (e.g., living conditions), the rating scales asked participants to indicate how adjusted they felt toward these factors rather than their perceptions of favorability per se. An alternative measure of outcome favor-

Table 2

Hierarchical Multiple Regression Results (Study 1)

\begin{tabular}{|c|c|c|c|}
\hline \multirow[b]{2}{*}{ Independent variable } & \multicolumn{3}{|c|}{ Thoughts of premature departure } \\
\hline & $\beta$ & $R^{2}$ & Change in $R^{2}$ \\
\hline Step 1 & & $.26 * *$ & $.26^{* *}$ \\
\hline Home office support & $.68 * *$ & & \\
\hline Successful repatriation & -.05 & & \\
\hline Previous overseas experience & & & \\
\hline Yes & 2.08 & & \\
\hline No & .00 & & \\
\hline Predeparture training & -.10 & & \\
\hline Step 2 & & $.43 * * *$ & $.17 * * *$ \\
\hline Procedural fairness & .21 & & \\
\hline Outcome favorability & $.40 * * *$ & & \\
\hline Step 3 & & $.50^{* * * *}$ & $.07 * *$ \\
\hline $\begin{array}{l}\text { Procedural Fairness } \times \\
\text { Outcome Favorability }\end{array}$ & $-.06 * *$ & & \\
\hline
\end{tabular}

ability consisted of an item which assessed the construct more directly (and more generally) than the measure reported above. Specifically, participants indicated on a 6-point rating scale their level of agreement with the following statement: "All in all, the benefits of my current assignment outweigh its costs." As might be expected, participants' evaluations on this alternative measure of outcome favorability item were significantly related to their evaluations on the previously reported measure of outcome favorability, $r(56)=.52, p<.001$.

We also conducted a hierarchical multiple regression in which the alternative measure of outcome favorability was substituted for the one used previously. Of greatest concern was whether the interaction between procedural fairness and the alternative measure of outcome favorability would be significant. In fact, it was, $F(1,50)=5.88, p<.025$, and took the same form as the one reported above. That is, outcome favorability was more strongly related to expatriates' thoughts of premature departure when procedural-fairness was relatively low rather than high. These findings provide converging evidence in support of the primary hypothesis. Furthermore, in conjunction with the significant correlation between the two measures of outcome favorability, the regression results provide evidence supporting the construct validity of the original measure of outcome favorability.

\section{Study 2}

Although the results of Study 1 supported the primary hypothesis, several methodological weaknesses should be noted. First, the sample size was fairly small $(N=58)$. Second, the internal consistency of the measure of procedural faimess was modest (.61). Given these shortcomings, it seemed worthwhile to attempt to replicate the findings; hence, a second study was conducted.

\section{Method}

Participants. Participants were 70 international assignees employed by a European-based consumer products company with significant international markets. The survey was mailed to all expatriates in the company; the response rate was $35 \%$. Participants were located in more than 40 countries spanning five continents. 
The average age of the participants in the sample was 40 years, and $95 \%$ of them were men. All of the participants in the main analyses were accompanied by a spouse or significant other. The group was largely composed of middle- to senior-level managers (e.g., directors, vice presidents, and regional general managers). Their average tenure with the company was 12 years. At the time the survey was administered, participants had been on assignment for an average of 1.6 years. The usual length of an international assignment in the organization was approximately 5 years.

Procedure. The procedure was highly similar to the one used in Study 1. Participants completed the survey in the context of the organization's efforts to assess its human resource practices. The survey was highly similar to the one used in Study 1. Because two of the control variables in Study 1-previous overseas experience and predeparture training-were unrelated to the dependent variable in both correlational analyses (see Table 1) and multiple regression (see Table 2, Step 1), they were deleted from Study 2 .

\section{Results}

Summary statistics for and correlations between all of the variables are reported in Table 3. As can be seen, all of the measures had acceptable internal reliabilities (including procedural fairness). Moreover, each of the independent variables and control variables was significantly related to participants' thoughts of premature departure and in the expected direction.

As in Study 1, a hierarchical multiple regression was conducted. In the first step, we entered the two control variables. As can be seen in Table 4, Step 1, only perceived support from the home office was significant $(p<.01)$. In the second step, we added the independent variables of outcome favorability and procedural fairness. Although neither effect was significant, outcome favorability was marginally related to thoughts of premature departure $(p<.08)$.

Finally, we added the interaction between outcome favorability and procedural fairness on the third step. As can be seen in Table 4, Step 3, the interaction was significant $(p<.025)$, and the sign of the beta was negative, as predicted. Subgroup analyses (analogous to those conducted in Study 1) further illustrated the nature of the interaction effect. Among those who perceived relatively low levels of procedural fairness, higher outcome favorability was associated with fewer thoughts of premature departure, $r(36)=.50, p<.01$. In contrast, among those who perceived relatively high levels of procedural fairness, the relationship between outcome favorability and thoughts of premature departure was not significant, $r(24)=.23, p>.15$.

\section{General Discussion}

Taken together, the results of both studies show that (nonwork) outcome favorability and procedural fairness combine interactively to predict expatriates' thoughts of premature departure. Although it may come as little surprise that participants thought more seriously about departing prematurely when their nonwork outcomes were relatively unfavorable, it is intriguing that the relationship between outcome favorability and thoughts of premature departure was significantly less pronounced when the organization's procedures were judged to be more fair. Both studies included control variables that have been linked to expatriates' thoughts of premature departure (e.g., perceived home office support). Thus, the interaction between procedural fairness and outcome favorability accounted for a significant portion of the variance beyond that attributable to the control variables. Furthermore, the fact that similar results emerged across two samples drawn from different countrics and industries bodes well for the generalizability of the findings.

\section{Theoretical Implications}

Expatriation. The extent to which expatriates successfully complete their overseas assignments is a matter of considerable significance to organizations and individuals alike. Extant models designed to predict premature expatriate departure, however, have not considered possible complexities in how the antecedent factors combine with each other, such as interaction effects between the antecedents. Drawing on recent research and theory in the organizational-justice literature (Brockner \& Wiesenfeld, 1996), the present studies hypothesized and found that important nonwork outcomes combine interactively with procedural fairness to predict the extent to which expatriates were seriously considering departing prematurely from their overseas assignments.

Organizational justice. Although the interaction between outcome favorability and procedural fairness has been found on numerous occasions (Brockner \& Wiesenfeld, 1996), the present studies enhance the generalizability of previous findings in two important respects. First, none of the preceding studies examined the interaction effect in the context of expatriates' reactions to their overseas assignments. Instead, many of the previous studies looked at the interaction between the outcomes and procedures associated with a significant organizational change, such as layoffs (Brockner et al., 1994), a pay freeze (Schaubroeck, May, \&

Table 3

Summary Statistics and Correlations (Study 2)

\begin{tabular}{lccccccc}
\hline \multicolumn{1}{c}{ Variable } & $M$ & $S D$ & 1 & 2 & 3 & 4 & 5 \\
\hline 1. Home office support & 3.41 & 0.95 & $(.77)$ & & & & \\
2. Successful repatriation & 2.62 & 0.88 & $.51^{* *}$ & $(.77)$ & & & \\
3. Outcome favorability & 5.53 & 0.80 & $.28^{*}$ & .19 & $(.81)$ & & \\
4. Procedural fairness & 3.84 & 0.78 & $.44^{* *}$ & $.32^{* *}$ & .15 & $(.70)$ & \\
5. Thoughts of premature departure & 4.35 & 0.92 & $.34^{* *}$ & $.30^{* *}$ & $.37^{* *}$ & $.32^{* *}$ & $(.74)$ \\
\hline
\end{tabular}

Note. Higher scores reflect greater levels of all variables except thoughts of premature departure, in which case higher scores reflect fewer thoughts of premature departure. All scores could range from 1-6. Coefficient alphas are in parentheses.

$* p<.05 . * * p<.01$. 
Table 4

Hierarchical Multiple Regression Results (Study 2)

\begin{tabular}{llcc}
\hline & \multicolumn{3}{c}{ Thoughts of premature departure } \\
\cline { 2 - 4 } Independent variable & $\beta$ & $R^{2}$ & Change in $R^{2}$ \\
\hline Step 1 & & $.22^{* * *}$ & $.22^{* * *}$ \\
$\quad$ Home office support & $.33^{* *}$ & & \\
$\quad \begin{array}{l}\text { Successful repatriation } \\
\text { Step 2 }\end{array}$ & .20 & & \\
$\quad$ Procedural fairness & .11 & $.26^{* * *}$ & .04 \\
$\quad$ Outcome favorability & .20 & & \\
Step 3 & & & \\
$\quad$ Procedural Faimess $\times$ & $-.21^{*}$ & $.32^{* * *}$ & $.06^{*}$ \\
$\quad$ Outcome Favorability & & & \\
\hline
\end{tabular}

${ }^{*} p<.025 .{ }^{* *} p<.01 . \quad * * * p<.001$.

Brown, 1994), and the introduction of a smoking ban (Greenberg, 1994).

Second, the outcomes examined in previous tests of the focal interaction effect in organizational settings always were work related. In contrast, the present studies dealt with perceptions of nonwork outcomes, such as expatriates' beliefs about the adjustment of their spouse/significant other, housing conditions, and health care management. Perceptions of nonwork outcomes may have been particularly meaningful to the current participants, given that all of them were accompanied by a spouse or significant other.

In fact, in both studies there also were a small number of expatriates who had not been accompanied by a spouse/significant other ( $N=17$ and 20 in Study 1 and Study 2, respectively). To evaluate whether nonwork outcomes interact with procedural fairness when those not accompanied by a spouse/significant other were included in the analyses, we computed a measure of nonwork outcome favorability that applied to all expatriates, regardless of whether they had been accompanied by a spouse/significant other. This was achieved by deleting the item tapping the perceived adjustment of the spouse/significant other; all other items tapping outcome favorability applied to all expatriates. We then repeated the hierarchical regression analyses conducted in Studies 1 and 2. Of greatest importance, the interaction between outcome favorability and procedural fairness took the same form (but was weaker) in both studies ( $p<.03$ in Study 1 , and $p<.11$ in Study 2).

One possible explanation of why the interaction effect became weaker is that the nonwork outcomes chosen for investigation (e.g., living conditions, health care management) were less important to expatriates who had not been accompanied by a spouse/ significant other relative to those who had been accompanied. To evaluate this possibility, we computed the correlation between outcome favorability and thoughts of premature departure separately for expatriates who had been accompanied by their spouse/ significant other versus those who had not. The correlation was significant among those who had been accompanied in both studies; $r=.45$ and .35 in Study 1 and Study 2 , respectively, $p<.01$. In contrast, the correlations were not significant among those who had not been accompanied by a spouse/significant other in both studies; $r=.15$ and .22 , respectively. Similar findings also were reported by Shaffer and Harrison (1998).

\section{Limitations and Suggestions for Future Research}

The present studies have a number of methodological and conceptual limitations. In discussing these limitations, we simultaneously are suggesting avenues for future research.

Correlational design. Given the methods used in the present research, the causal impact of the interaction between outcome favorability and procedural fairness on expatriates' thoughts of premature departure has not been definitively established. On the basis of previous studies examining the interactive effect of outcome favorability and procedural faimess, however, there is reason to believe that the interaction between these two independent variables was causally related to the dependent variable in the present studies. Many of the previous demonstrations of the interaction between outcome favorability and procedural fairness were obtained when one or both of the independent variables were experimentally manipulated (e.g., Folger \& Martin, 1986; Folger, Rosenfield, \& Robinson, 1983; Greenberg, 1987, 1994). The fact that the interaction has been found repeatedly in well-controlled studies suggests that the present findings have internal validity. However, the interactive effect of outcome favorability and procedural fairness on expatriates still needs to be explored in future research with methods that allow for stronger forms of causal inference.

Common methods. Another possible limitation of the present studies is that the results may have been an artifact of common methods. Although this alternative explanation cannot be eliminated entirely, the fact that the primary findings were interaction effects makes the common-methods explanation less compelling. Participants in both studies completed measures of procedural fairness, outcome favorability, and thoughts of premature departure in the same survey at the same point in time. Whereas the common-methods account may explain why the three measures generally were correlated with each other, it is less able to explain why the relationships between variables were more pronounced under some conditions than others. For example, the relationship between outcome favorability and thoughts of premature departure was stronger when procedural fairness was relatively low rather than high.

Dependent variable. A basic premise of the present studies is that premature departure is one operational definition of the success or failure of an expatriate assignment. Participants' actual level of premature departure was not measured in the present studies. Rather, we assessed the extent to which they thought seriously about leaving. Several turnover models (Mobley, 1982; Naumann, 1992) suggest that individuals who quit usually think seriously about doing so prior to their departure. Thus, it is useful to identify the factors that affect expatriates' thoughts of premature departure (Shaffer \& Harrison, 1998; Steel \& Ovalle, 1984). However, it is important for future researchers to evaluate whether the interaction between outcome favorability and procedural fairness similarly predicts actual premature departure.

Accounting for the interaction effect. Numerous theories have been offered that can account for the interaction between outcome favorability and procedural fairness; see Brockner and Wiesenfeld (1996) for a review. One theory that is quite compatible with the present findings is the updated version of referent cognitions theory (Folger, 1993). According to this viewpoint, people are particularly resentful toward a party whom they associate with 
unfavorable outcomes when they view the party as responsible for, or intentionally causing, the unfavorable outcomes. When the party is seen as less responsible for, or less intentionally causing, unfavorable outcomes, resentment toward the party will be muted. The present findings suggest that expatriates who viewed procedures to be more fair may have perceived the organization as less responsible for unfavorable nonwork outcomes relative to those who perceived procedures to be less fair. For example, those who perceived procedures to be more unfair may have blamed the organization more for not arranging better living conditions for them, thereby eliciting more serious thoughts of premature departure.

Although the present findings are consistent with referent cognitions theory, they also are at least somewhat compatible with other explanations of the interaction effect (Lind \& Tyler, 1988; Thibaut \& Walker, 1975). The present studies did not evaluate the relative merits of the various explanations of the interactive relationship between outcome favorability and procedural faimess, nor were they intended to. Thus, future research is needed to ascertain more definitively why expatriates' thoughts of premature departure were more strongly related to outcome favorability when procedural faimess was low rather than high.

\section{Practical Implications}

Many of the factors examined in previous research on premature expatriate departure are proximal to the expatriation process, for example, whether the right people are selected or whether the organization provides adequate levels of predeparture and onassignment training and support for managers and accompanying family members (Black et al., 1991; Naumann, 1992). The present findings suggest that organizational authorities also need to attend to the fairness of their ongoing procedures, which are more distal to the expatriation process but nevertheless may influence expatriates' reactions to their overseas assignments. In fact, proximal factors such as the favorability of living conditions interact with distal factors such as procedural fairness to predict expatriates' thoughts of premature departure.

The present studies also have important implications for organizations seeking to minimize the extent to which expatriates are thinking seriously about departing prematurely. On the one hand, it could be argued that organizations can reduce the odds of premature departure by trying to ensure that the expatriates receive favorable nonwork outcomes. On the other hand, organizations may encounter at least two problems in their attempts to provide favorable outcomes outside of the workplace. First, many of the relevant outcomes (e.g., adjustment of family members) may not be under the organization's direct control. Second, it may not be economically feasible to provide expatriates with favorable outcomes. In fact, many globally oriented organizations are under increasing cost pressures to minimize the perquisites often associated with international transfers (Brewster, 1997). The nature of the interaction effect suggests that nonwork outcome favorability may be less consequential as long as the organization's procedures are seen as fair. Although it may be challenging for managers to ensure that the institution's procedures are fair, the economic or material costs associated with ensuring procedural faimess are likely to be far less than those needed to produce favorable nonwork outcomes (Folger \& Pugh, 1999). In short, the present findings may help organizations find cost effective ways to minimize the extent to which their international assignees seriously contemplate departing prematurely.

\section{References}

Adler, N. (1996). International dimensions of organizational behavior (3rd ed.). Boston: PWS-Kent Publishing Co.

Ajzen, I., \& Fishbein, M. (1980). Understanding attitudes and predicting social behavior. Englewood Cliffs, NJ: Prentice-Hall.

Bies, R. J. (1987). The predicament of injustice: The management of moral outrage. In L. L. Cummings \& B. M. Staw (Eds.), Research in organizational behavior (Vol. 9, pp. 289-319). Greenwich, CT: JAI Press.

Bird, A., \& Dunbar, R. (1991, Spring). Getting the job done over there: Improving expatriate effectiveness. National Productivity Review, 145156.

Black, J. S., Gregersen, H. B., \& Mendenhall, M. E. (1992). Global assignments. San Francisco: Jossey-Bass.

Black, J. S., Mendenhall, M., \& Oddou, G. (1991). Toward a comprehensive model of international adjustment: An integration of multiple theoretical perspectives. Academy of Management Review, 16, 291-317.

Blau, P. (1964). Exchange and power in social life. New York: Wiley.

Brewster, C. (1997). International human resource management: Beyond expatriation. Human Resource Management Journal, 7, 31-40.

Brockner, J., Konovsky, M., Cooper-Schneider, R., Folger, R., Martin, C. L., \& Bies, R. J. (1994). The interactive effects of procedural justice and outcome negativity on the victims and survivors of job loss. Academy of Management Joumal, 37, 397-409.

Brockner, J., \& Wiesenfeld, B. M. (1996). An integrative framework for explaining reactions to decisions: The interactive effects of outcomes and procedures. Psychological Bulletin, 120, 189-208.

Folger, R. (1993). Reactions to mistreatment at work. In J. K. Murnighan (Ed.), Social psychology in organizations: Advances in theory and research (pp. 161-183). Englewood Cliffs, NJ: Prentice-Hall.

Folger, R., \& Greenberg, J. (1985). Procedural justice: An interpretive analysis of personnel systems. In K. Rowland \& G. Ferris (Eds.), Research in personnel and human resource management (Vol. 3, pp. 141-183). Greenwich, CT: JAI Press.

Folger, R., \& Martin, C. L. (1986). Relative deprivation and referent cognitions: Distributive and procedural justice effects. Journal of Experimental Social Psychology, 22, 531-546.

Folger, R., \& Pugh, S. D. (1999). The Churchill paradox in managing hard times: Kicking employees when they're down and out. Manuscript submitted for publication.

Folger, R., Rosenfield, D., \& Robinson, T. (1983). Relative deprivation and procedural justification. Journal of Personality and Social Psychology, 45, 268-273.

Grant, L. (1997, April). That overseas job could derail your career. Fortune, $135,166$.

Greenberg, J. (1987). Reactions to procedural justice in payment allocations: Do the ends justify the means? Journal of Applied Psychology, 72, 55-61.

Greenberg, J. (1990). Organizational justice: Yesterday, today, and tomorrow. Journal of Management, 16, 399-432.

Greenberg, J. (1994). Using socially fair treatment to promote acceptance of a work site smoking ban. Journal of Applied Psychology, 79, 288297.

Greenberg, J. (1996). The quest for justice on the job: Essays and experiments. Thousand Oaks, CA: Sage.

Gregersen, H., \& Black, J. S. (1992). Antecedents of commitment to a parent company and a foreign operation. Academy of Management Journal, 35, 65-90.

Hay/McBer Co. (1996). The international assignment inventory. Boston: Hay/McBer Publications. 
Hay/McBer Co. (1997). Organizational climate survey II. Boston: Hay' McBer Publications.

Leventhal, G., Karuza, J., \& Fry, W. R. (1980). Beyond fairness: A theory of allocation preferences. In G. Mikula (Ed.), Justice and social interaction (pp. 167-218). New York: Springer-Verlag.

Lind, E. A., \& Tyler, T. R. (1988). The social psychology of procedural justice. New York: Plenum.

McClelland, D. C., \& Burnham, D. H. (1995). Power is the great motivator. Harvard Business Review, 95, 126-139.

Milkovich, G. T., \& Newman, J. M. (1996). Compensation (5th ed.). Chicago: Richard D. Irwin.

Mobley, W. H. (1982). Employee turnover: Causes, consequences, and control. Reading, MA: Addison-Wesley.

Naumann, E. (1992). A conceptual model of expatriate turnover. Journal of International Business Studies, 3, 499-531.

Schaubroeck, J., May, D. R., \& Brown, F. W. (1994). Procedural justice explanations and employee reactions to economic hardship: A field experiment. Journal of Applied Psychology, 79, 455-460.

Shaffer, M. A., \& Harrison, D. A. (1998). Expatriates' psychological withdrawal from international assignments: Work, nonwork, and family influences. Personnel Psychology, 51, 87-118.

Steel, R. P., \& Ovalle, N. K. (1984). A review and meta-analysis of research on the relationship between behavioral intentions and employee turnover. Journal of Applied Psychology, 69, 673-686.

Thibaut, J., \& Walker, L. (1975). Procedural justice: A psychological analysis. Hillsdale, NJ: Erlbaum.

Received July 22, 1998

Revision received February 15, 1999

Accepted February 17, 1999

\section{Instructions to Authors \\ Journal of Applied Psychology}

Articles submitted for publication in the Journal of Applied Psychology are evaluated according to the following criteria: (a) significance of contribution, (b) technical adequacy, (c) appropriateness for the journal, and (d) clarity of presentation. In addition, articles must be clearly written in concise and unambiguous language and must be logically organized. The goal of APA primary journals is to publish useful information that is accurate and clear.

Authors should prepare manuscripts according to the Publication Manual of the American Psychologicul Association (4th ed.). Articles not prepared according to the guidelines of the Manual will not be reviewed. All manuscripts must include an abstract containing a maximum of 960 characters and spaces (which is approximately 120 words) typed on a separate sheet of paper. Typing instructions (all copy must be double-spaced) and instructions on preparing tables, tigures, references, metrics, and abstracts appear in the Manual. Also, all manuscripts are copyedited for biasfree language (see chap. 2 of the Publication Manual). Original color figures can be printed in color provided the author agrees to pay half of the associated production costs.

The journal will publish both regular articles, or Feature Articles, and Research Reports. Authors can refer to recent issues of the journal for approximate length of Feature Articles. (Total manuscript pages divided by 3 provides an estimate of total printed pages.) Longer articles will be considered for publication, but the contribution they make must justify the number of journal pages needed to present the research. Research Reports feature shorter manuscripts that make a distinct but relatively narrow contribution, such as important replications or studies that discuss specific applications of psychology. Authors may request Research Report status at the time of submission, or the editor may suggest that a regular-length submission be pared down to Research Report length. Research Reports are limited to no more than 17 pages of text proper; these limits do not include the title page, abstract, references, tables, or figures. Different printers, fonts, spacing, margins, and so forth can substantially alter the amount of text that can be fit on a page. In determining the length limits of Research Reports, authors should count 25-26 lines of text (60 characters per line) as the equivalent of one page.

APA policy prohibits an author from submitting the same manuscript for concurrent consideration by two or more publications. In addition, it is a violation of APA Ethical Principles to publish "as original data, data that have been previously published" (Standard 6.24). As this journal is a primary journal that publishes original material only. APA policy prohibits as well publication of any manuscript that has already been published in whole or substantial part elsewhere. Authors have an obligation to consult journal editors concerning prior publication of any data upon which their article depends. In addition, APA Ethical Principles specify that "after research results are published, psychologists do not withhold the data on which their conclusions are based from other competent professionals who seek to verify the substantive claims through reanalysis and who intend to use such data only for that purpose, provided that the confidentiality of the participants can be protected and unless legal rights concerning proprietary data preclude their release" (Standard 6.25). APA expects authors submitting to this journal to adhere to these standards. Specifically, authors of manuscripts submitted to APA journals are expected to have their data available throughout the editorial review process and for at least 5 years after the date of publication.

Authors will be required to state in writing that they have complied with APA ethical standards in the treatment of their sample, human or animal, or to describe the details of treatment. A copy of the APA Ethical Principles may be obtained by writing the APA Ethics Office, 750 First Street, NE, Washington, DC 20002-4242 (or see "Ethical Principles,'” December 1992, American Psychologist, Vol. 47, pp. 1597-1611).

The journal will accept submissions in masked (blind) review format only. Each copy of a manuscript should include a separate title page with author names and affiliations, and these should not appear anywhere else on the manuscript. Furthermore, author identification notes should be typed on the title page (see Manual). Authors should make every reasonable effort to see that the manuscript itself contains no clues to their identities. Manuscripts not in masked format will not be reviewed.

Authors must submit five (5) copies of the manuscript. The copies should be clear, readable, and on paper of good quality. A dot matrix or unusual typeface is acceptable only if it is clear and legible. In addition to addresses and phone numbers, authors should supply electronic mail addresses and fax numbers, if available, for potential use by the editorial office and later by the production office. Authors should keep a copy of the manuscript to guard against loss. Mail manuscripts to Kevin R. Murphy, Editor, Department of Psychology, Colorado State University, Fort Collins, Colorado 80523-1876. 